Gazi University
Journal of Science
http://dergipark.gov.tr/gujs

\title{
The Effect of Annealing Technique on ZnO Film Properties
}

\author{
Meryem POLAT GONULLU* \\ Gazi University, Department of Metallurgical and Materials Engineering, 06500, Ankara, Turkey
}

\author{
Highlights \\ - This paper focuses on the effect of the annealing technique on $\mathrm{ZnO}$ film properties. \\ - Microwave and standard thermal annealing techniques are applied to the films. \\ - Improved crystalline properties were determined for microwave annealed $\mathrm{ZnO}$ films.
}

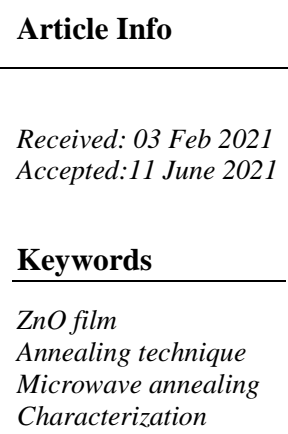

\section{INTRODUCTION}

Zinc oxide $(\mathrm{ZnO})$ is a member of the group II-VI family with fascinating properties such as wide and direct optical band gap $(\sim 3.37 \mathrm{eV})$, large excitation binding energy $(\sim 60 \mathrm{meV})$ at room temperature, chemical and thermal stability [1-3], etc. As a result of these features, $\mathrm{ZnO}$ has gained extensive research potential in technological applications from optoelectronic devices to photocatalysis [4, 5]. Various production methods are applicable for the production of $\mathrm{ZnO}$ films including chemical vapor deposition (CVD), physical vapor deposition (PVD), ultrasonically spray pyrolysis (USP), atomic layer deposition (ALD), and sputtering [610]. Among these methods, ultrasonically spray pyrolysis provides low cost, large area deposition, ease of use and easy modification facility. Requiring no vacuum is also another advantage of spray pyrolysis. In this technique, the films are deposited by spraying the starting solution onto pre-heated substrates. An ultrasonic atomizer is utilized to atomize starting solution to produce thin or thick films. Different type of substrates can be used for the coating with different geometries. By adjusting the production parameters such as spray nozzle to substrate distance, substrate temperature, starting solution molarity, solution flow rate, and solution solvent type etc. physical properties of spray deposited films can be changed $[11,12]$.

Crystallization of $\mathrm{ZnO}$ structures occurs in three forms. These are the hexagonal wurtzite that is the most stable and most common phase, zinc blende that is metastable structure, and rocksalt structure which is transformed from wurtzite structure under high-pressure conditions [13]. Occurring of these structures is related to production methods, process parameters, and substrate type [14-16], etc. In order to improve the 
physical properties of $\mathrm{ZnO}$ and increasing potential applications, annealing is an effective approach. For this purpose, many investigations have been made using a variety of annealing conditions such as atmosphere annealing, atmosphere-controlled annealing in nitrogen, argon, and oxygen ambient, and rapid thermal annealing (RTA) [17-21], etc. Besides, the microwave (MW) annealing method which is attracting attention lately in semiconductor-based materials provides advantages with improved crystal properties according to classical methods [22].

In line with this information, this work is focused on the effect of the annealing technique on structural, morphological, compositional, and optical properties of $\mathrm{ZnO}$ films produced by the USP technique. Thus, $\mathrm{ZnO}$ films have been annealed with standard thermal annealing (STA) and microwave annealing (MW) techniques at $600^{\circ} \mathrm{C}$ for 1 hour. As-deposited and annealed films have been characterized and resulting film properties have been discussed.

\section{EXPERIMENTAL}

$\mathrm{ZnO}$ films have been deposited on microscope glass substrates by the USP technique at a substrate temperature of $400 \pm 5^{\circ} \mathrm{C}$ using air as carrier gas with a pressure of $1 \mathrm{~atm}$. The schematic diagram and working principle of the USP technique are given in detail in previous work [23]. The ultrasonic oscillator frequency has been arranged at $100 \mathrm{kHz}$. The spraying solution has been prepared by dissolving $0.1 \mathrm{M}$ $\left[\left(\mathrm{CH}_{3} \mathrm{COO}\right)_{2} \mathrm{Zn} .2 \mathrm{H}_{2} \mathrm{O}\right]$ in deionized water to produce $\mathrm{ZnO}$ film. Totally $120 \mathrm{cc}$ of the solution has been sprayed onto glass substrates for $30 \mathrm{~min}$. The solution flow rate has been kept at $4 \mathrm{cc} \mathrm{min}^{-1}$ and controlled by a flowmeter. After the production, films have been annealed at $600^{\circ} \mathrm{C}$ for 1 hour by two different annealing techniques which are standard thermal annealing (STA) (PROTHERM) and microwave annealing (MWA) (SYNOTHERM, $800 \mathrm{~W}$ ) in air atmosphere. The samples are named as Z-As, Z-STA, and Z-MWA according to the as-deposition and annealing technique. Structural analysis of the samples has been performed by Bruker D8 Advanced diffractometer with $\mathrm{CuK}_{\alpha}(1.5418 \AA)$ radiation. Surface morphologies, film thicknesses, and the elemental compositions of the films have been investigated by Jeol JSM 6060LV Scanning electron microscope (SEM) equipped with IXRF systems. Optical properties have been analyzed by Shimadzu UV-Visible model 2600 spectrophotometer in the range of $200 \mathrm{~nm}$ to $700 \mathrm{~nm}$. The PL spectra have been measured by a Horiba Jobin Yvon Fluorolog-3spectrometer with $325 \mathrm{~nm} \mathrm{He}-\mathrm{Cd}$ laser.

\section{RESULT AND DISCUSSION}

X-ray diffraction (XRD) patterns of Z-As, Z-STA, and Z-MWA films are shown in Figure 1. It has been determined that the peaks seen from XRD spectra well match with the peaks in the ICDD card: 36-1451. The presence of peaks corresponding to (100), (002), (101), (102), (110), (103), (200), (112), and (201) planes with different intensities (indicated by a line equal to 5000 counts) related to the hexagonal wurtzite crystal structure of $\mathrm{ZnO}$ exhibit the polycrystalline nature of the films. 


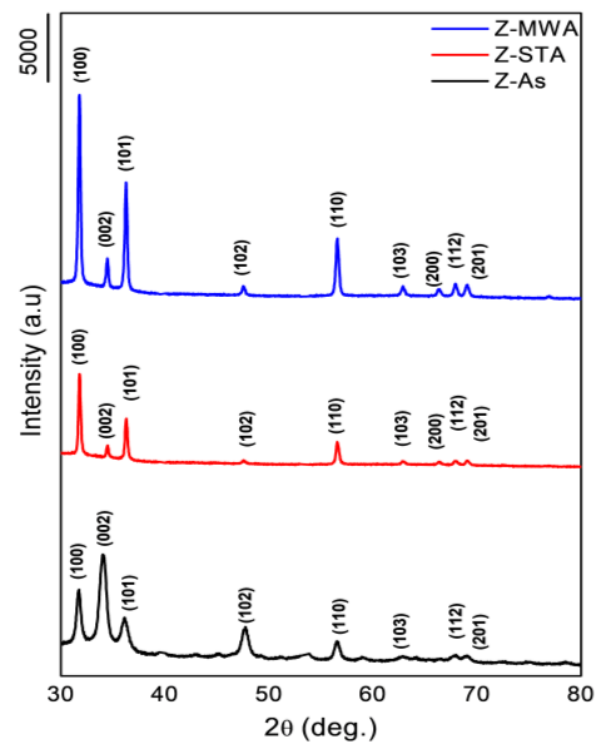

Figure 1. XRD patterns of Z-As, Z-STA, and Z-MWA films

Table 1 shows the data related to three major peaks with different intensities and widths on XRD patterns with ICDD (Card No: 36-1451) values. An obvious increase in the diffraction intensity of Z-MWA film reveals the higher crystallinity level after the microwave annealing of $\mathrm{ZnO}$ film. Also, shifting in the peak positions and decreasing interplanar spacing to the ICDD values, and decreasing in full width half maximum $(\beta)$ values are seen for Z-STA and Z-MWA films according to Z-As film.

Table 1. Data related to three major peaks from XRD patterns with ICDD values

\begin{tabular}{|l|l|l|l|l|l|l|l|l|}
\hline Sample & $\begin{array}{l}\text { Miller } \\
\text { Indice }\end{array}$ & $2 \theta$ & $2 \theta_{0}$ & $\mathrm{I}$ & $\mathrm{I}_{0}$ & $\mathrm{~d}$ & $\mathrm{~d}_{0}$ & $\beta$ \\
\hline \multirow{3}{*}{ Z-As } & $(100)$ & 31.701 & 31.770 & 6463 & 58 & 2.82026 & 2.81430 & 0.472 \\
\cline { 2 - 9 } & $(002)$ & 34.038 & 34.422 & 9159 & 45 & 2.63183 & 2.60332 & 0.738 \\
\cline { 2 - 10 } & $(101)$ & 36.124 & 36.253 & 4412 & 101 & 2.48444 & 2.47592 & 0.638 \\
\hline \multirow{2}{*}{ Z-STA } & $(100)$ & 31.792 & 31.770 & 7365 & 58 & 2.81242 & 2.81430 & 0.247 \\
\cline { 2 - 10 } & $(002)$ & 34.514 & 34.422 & 1982 & 45 & 2.59659 & 2.60332 & 0.236 \\
\cline { 2 - 10 } & $(101)$ & 36.283 & 36.253 & 4012 & 101 & 2.47393 & 2.47592 & 0.274 \\
\hline \multirow{2}{*}{ Z-MWA } & $(100)$ & 31.792 & 31.770 & 15963 & 58 & 2.81242 & 2.81430 & 0.260 \\
\cline { 2 - 9 } & $(002)$ & 34.469 & 34.422 & 3619 & 45 & 2.59991 & 2.60332 & 0.253 \\
\cline { 2 - 9 } & $(101)$ & 36.261 & 36.253 & 9342 & 101 & 2.47543 & 2.47592 & 0.272 \\
\hline
\end{tabular}

The other structural parameters such as texture coefficient $(\mathrm{P})$, crystallite size (D), dislocation density $(\delta)$, and microstrain $\langle\mathrm{e}\rangle$ values have also been evaluated which are given in Table 2 and calculated by following relations $[24,25]$;

$$
\begin{aligned}
& P\left(h_{i} k_{i} l_{i}\right)=\frac{I\left(h_{i} k_{i} l_{i}\right)}{I_{o}\left(h_{i} k_{i} l_{i}\right)}\left[\frac{1}{n} \sum_{i=1}^{n} \frac{I\left(h_{i} k_{i} l_{i}\right)}{I_{o}\left(h_{i} k_{i} l_{i}\right)}\right]^{-1}, \\
& D=\frac{0.9 \lambda}{\beta \cos \theta}, \\
& \delta=\left(\frac{1}{D}\right)^{2}, \\
& \varepsilon=\frac{d-d_{o}}{d_{o}} .
\end{aligned}
$$

Here, $I_{o}$ is the standard intensity (ICDD), $I$ is the observed intensity of $\left(h_{i} k_{i} l_{i}\right)$ plane, $n$ is the reflection number, $\beta$ is the half-width of the peak with maximum intensity as radian, $D$ is the crystallite size, $\lambda$ is the 
wavelength of X-ray, $\theta$ is the Bragg angle, $d$ is the interplanar spacing and $d_{o}$ is the interplanar spacing without deformation [24, 25]. Surface tensions, strains between the glass substrate and polycrystalline film, and inner strains as residual stresses in the film have been neglected.

The evaluated structural parameters have also been determined for three intense peaks of the $\mathrm{ZnO}$ structure. From the XRD parameters, it has been obtained that Z-As film shows preferential orientation $(\mathrm{P})$ which is highlighted in bold type, through the (002) diffraction plane. Also, an alteration has been determined for preferential orientations of Z-STA and Z-MWA films from (002) to (100) diffraction plane after the thermal annealing. This rearrangement of the crystal orientations has been associated with increasing oxygen ratio in the literature $[26,27]$. Also, it can be said that these increased texture coefficient values of the annealed films indicate increasing crystallites.

Table 2. Calculated structural parameters of ZnO films

\begin{tabular}{|l|l|l|l|l|l|}
\hline Sample & Miller Indice & $\mathrm{P}$ & $\mathrm{D}(\mathrm{nm})$ & $<\mathrm{e}$ & $\delta\left(\right.$ line $\left./ \mathrm{nm}^{2}\right)$ \\
\hline \multirow{4}{*}{ Z-As } & & & & \\
\cline { 2 - 6 } & $(100)$ & 0.932094 & 17.518 & $2.12 \mathrm{E}-03$ & $3.26 \mathrm{E}-03$ \\
\cline { 2 - 6 } & $(002)$ & $\mathbf{1 . 7 0 2 5 0 7}$ & 11.271 & $1.10 \mathrm{E}-02$ & $7.87 \mathrm{E}-03$ \\
\hline \multirow{3}{*}{ Z-STA } & $(101)$ & 0.365399 & 12.232 & $3.44 \mathrm{E}-03$ & $6.68 \mathrm{E}-03$ \\
\cline { 2 - 6 } & $(100)$ & $\mathbf{1 . 8 0 7 5 8 3}$ & 33.484 & $-6.68 \mathrm{E}-04$ & $8.92 \mathrm{E}-04$ \\
\cline { 2 - 6 } & $(1002)$ & 0.626967 & 35.293 & $-2.59 \mathrm{E}-03$ & $8.03 \mathrm{E}-04$ \\
\hline \multirow{3}{*}{ Z-MWA } & $(100)$ & 0.565449 & 30.548 & $-8.04 \mathrm{E}-04$ & $1.07 \mathrm{E}-03$ \\
\cline { 2 - 6 } & $(002)$ & $\mathbf{1 . 8 4 2 4 3 7}$ & 31.809 & $-6.68 \mathrm{E}-04$ & $9.88 \mathrm{E}-04$ \\
\cline { 2 - 6 } & $(101)$ & 0.538372 & 32.917 & $-1.31 \mathrm{E}-03$ & $9.23 \mathrm{E}-04$ \\
\hline
\end{tabular}

From Table 2, it can be seen that the crystallite size (D) values of $\mathrm{ZnO}$ films have been varied in the range of 11-35 nm. This increase in the crystallite sizes of Z-STA and Z-MWA films indicates the decreasing grain boundaries in the film structure. Also, almost the same crystallite sizes have been determined for annealed films. Dislocation density $(\delta)$ values that show the number of dislocation lines per unit volume have been detected minimum for Z-MWA film. The lowest value of dislocation density indicates the decreasing defects in the film structure and increasing film quality for microwave annealed film. Also, negative microstrain values have been obtained for annealed films that indicating the reduction of compressive stresses in the film as defined by Equation (4) according to Z-As. Generally, it can be said that the Z-STA and Z-MWA films have enhanced properties according to Z-As film to the data obtained. However, among the annealed films, Z-MWA film highlights its improved features like highest crystallinity level, $2 \theta$ and interplanar $d$ spacing values closest to standard, while Z-STA film has better $\beta$ and microstrain values that almost the same with Z-MWA film.

The surface images of Z-As, Z-STA, and Z-MWA films have been taken by SEM at X30 magnification plan-view, X1000, and X3000 (inset image) magnification in detail and given in Figure 2. Smooth surface properties have been obtained for all films from the SEM images taken at X30 magnification that indicate the uniform deposition on the substrate surface. The micrographs taken at X1000 magnification presents the detailed surface morphology of $\mathrm{ZnO}$ films with droplet trails related to spraying. Also, root-like areas are seen in these images and given in inset images taken at X3000 magnification, in detail. An increasing trend has been determined in the root-like morphology of the Z-STA and Z-MWA films that are may be related to the relaxation of stress in the structure of the films as a result of annealing. Xu Li et al. [28], explain this formation with the effect of annealing process while H. Sutanto et al. [29], explain it with temperature difference between the first and other layers which causes the merging particles to make a long $\mathrm{ZnO}$ structure. K. Navin et al. [30], also clarify this phenomenon by changing the decomposition rate of precursor solutions and evaporation of the solvent by changing the heating rate. S.J Kwon et al. [31], also reported formation of root-like network morphology which is caused by the relaxation of stress as a result of the evaporation of solvent. Another possible mechanism has been explained by Scherer et al. [32], as loss of hydroxyl/alkoxy group by heating process for the production of these formations. In this study, this 
root-like type formation is thought to be in a relationship with the relaxation of stress after annealing besides evaporation of precursor solution during the production process on heated substrates.

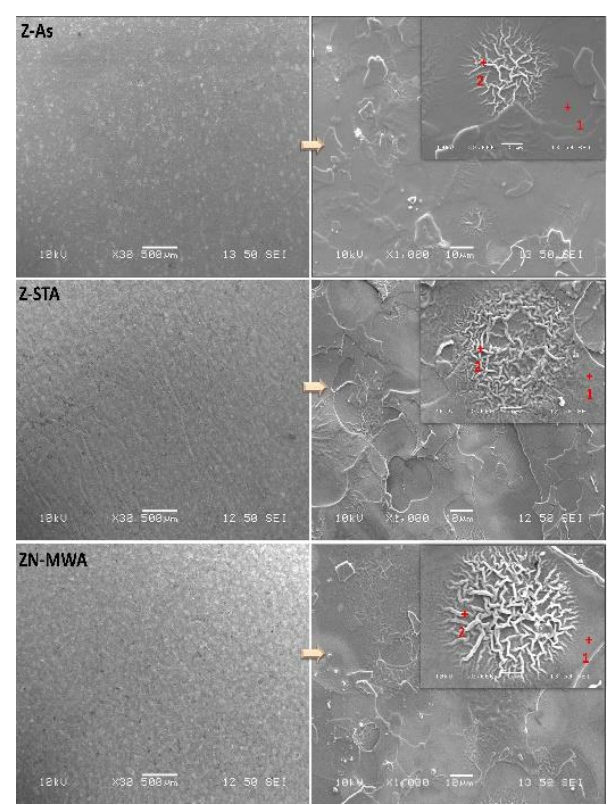

Figure 2. SEM images of Z-As, Z-STA, and Z-MWA films

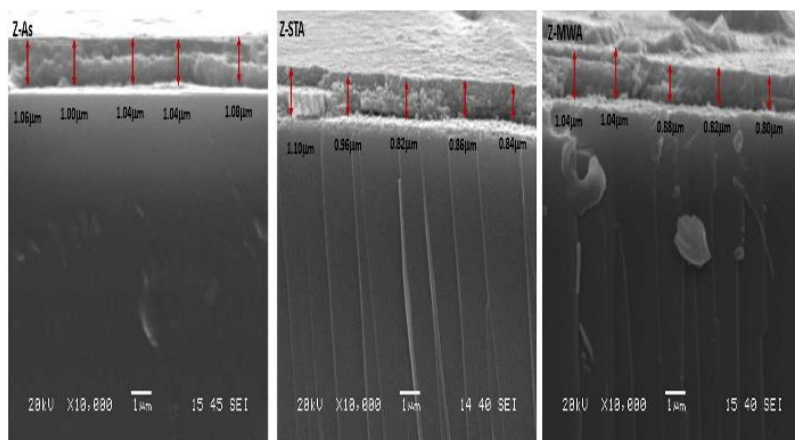

Figure 3. Cross-sectional SEM images of Z-As, Z-STA, and Z-MWA films with their thicknesses that obtained five different location

Thicknesses of the films have been obtained by cross-sectional SEM images that are given in Figure 3. From these figures, average thickness of Z-As film has been obtained as $1.04 \mu \mathrm{m}$. After the annealing at different conditions, it has been determined that the thicknesses of the Z-STA and Z-MWA changed to 0.92 $\mathrm{nm}$ for both films. This decreasing in the thicknesses could be attributed to the transforming of the films to the more ordered phases, reduced defects, and dimensional changes. This situation also could be explained by desorption of atoms by substrate surface as a result of increasing temperature with the effect of annealing.

Energy dispersive X-Ray spectroscopy (EDX) has been used to obtain detailed information about film compositions. In Figure 4, only the spectra of the plan-view images have been presented in order to avoid visual confusion due to the similarity of EDX spectra to each other. In these spectra, the presence of zinc, oxygen, and silicon (comes from the glass substrate and neglected) elements are observed. Also, elemental compositions have been individually investigated on the plan-view, matrix (marked as 1), and root-like (marked as 2) regions to exhibit the distribution of the oxygen and zinc elements in the different regions of whole structure. Atomic weights (at\%) of $\mathrm{Zn}$ and $\mathrm{O}$ elements and $\mathrm{O} / \mathrm{Zn}$ ratio from these regions are listed in Table 3. 


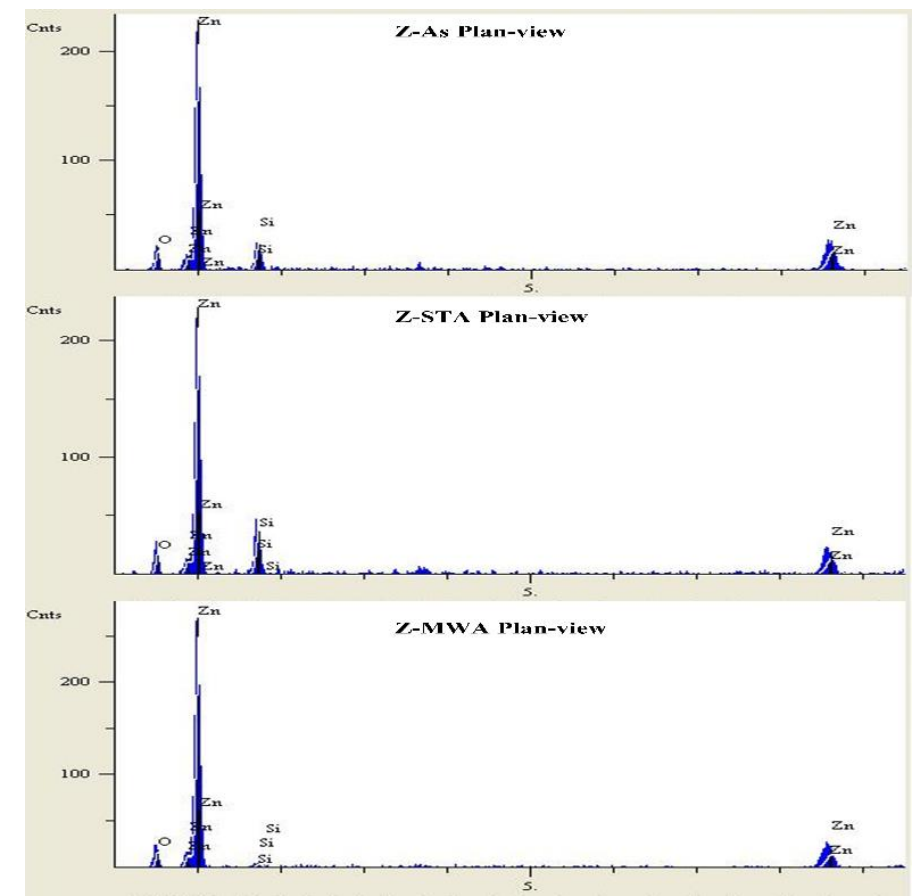

Figure 4. EDX spectra of Z-As, Z-STA, and Z-MWA films from the plan-view

Table 3. Elemental compositions and O/Zn ratio of ZnO films

\begin{tabular}{|c|c|c|c|c|}
\hline \multirow{2}{*}{ Sample } & Selected Area & O at\% & Zn at\% & O/Zn ratio \\
\hline \multirow{3}{*}{ Z-As } & Plain-view & 42.498 & 57.502 & 0.739 \\
\cline { 2 - 5 } & Matrix & 28.676 & 71.324 & 0.402 \\
\cline { 2 - 5 } & Root-like & 38.820 & 61.180 & 0.635 \\
\hline \multirow{3}{*}{ Z-STA } & Plain-view & 49.538 & 50.462 & 0.982 \\
\cline { 2 - 5 } & Matrix & 38.536 & 61.464 & 0.627 \\
\cline { 2 - 5 } & Root-like & 45.127 & 54.873 & 0.822 \\
\hline \multirow{3}{*}{ Z-MWA } & Plain-view & 45.989 & 54.011 & 0.851 \\
\cline { 2 - 5 } & Matrix & 42.869 & 57.131 & 0.750 \\
\cline { 2 - 5 } & Root-like & 43.915 & 56.085 & 0.783 \\
\hline
\end{tabular}

Compositional distributions of $\mathrm{O}$ and $\mathrm{Zn}$ elements obtained from plan-view images (X30) that give the data from the larger area of the films present the increasing film stoichiometry. This is may be attributed to the oxidation of the Z-STA and Z-MWA films after the annealing under the air atmosphere. Also, Z-STA film presents the higher stoichiometry from the plan-view analysis in all films. Detailed investigations evaluated on the matrix and root-like formations given in the inset images at X3000 magnification present the Z-As film has excess $\mathrm{Zn}$ element for all regions that indicates the non-uniform distributions of the elements. Besides, annealed films indicate the improved and more homogeneous distribution of oxygen and zinc elements in their structures. Although the Z-STA film exhibits improved stoichiometry from the plan-view analysis, it can be seen from Table 3 that the Z-MWA film has higher homogeneity between the matrix and root-like regions that indicates the better distribution of elements in its structure. This is another proof that the evaporation of the precursor solution during the production process and annealing in the oxygen atmosphere improves the compositions of the films.

Absorbance spectra of the as-deposited and annealed $\mathrm{ZnO}$ films are shown in Figure 5. 


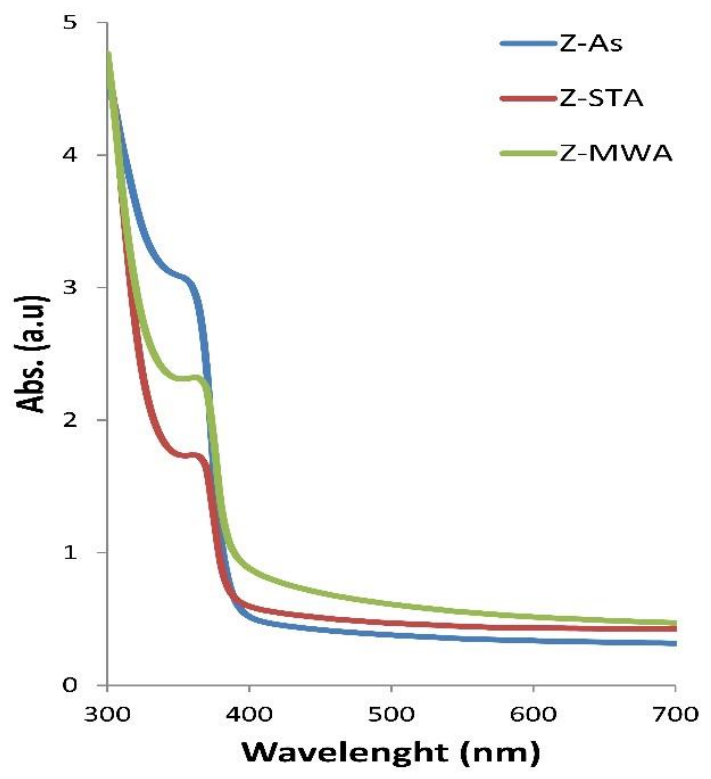

Figure 5. Absorbance spectra of Z-As, Z-STA, and Z-MWA films

Fundamental absorption edges have been observed at almost similar wavelengths from the absorption spectra of the films. Using these absorption spectra of the films, $(\alpha h v)^{2}-(h v)$ plots have been obtained and optical band gap values of the $\mathrm{ZnO}$ films have been determined by optical method which is given in Figure 6. As a result, it has been determined that as-deposited and annealed films have direct band gap transitions. The optical band gap values have been obtained as 3.27, 3.23, and 3.21 eV for Z-As, Z-STA, and Z-MWA films, respectively. Also, decreased band gap values according to bulk $\mathrm{ZnO}$ have been determined for annealed films that could be associated with improved crystal properties. Especially, a distinct decreasing has been obtained for optical band gap values of Z-MWA film from 3.27 to $3.21 \mathrm{eV}$. In the earlier reports, J. Gonioakowski and C. Noguera have been explained this situation with the various lattice associated atomic interaction phenomena occurring from ionic crystalline lattice nature of $\mathrm{ZnO}$. Caglar et. al,, Sengupta et. al., and Ghosh et. al. have also identified this with increasing crystallinity as a result of reducing defects and stress as seen in the XRD result of this study [33-36]. This band gap narrowing of the absorption edge toward higher wavelengths allows for visible light driven photocatalytic applications [37].

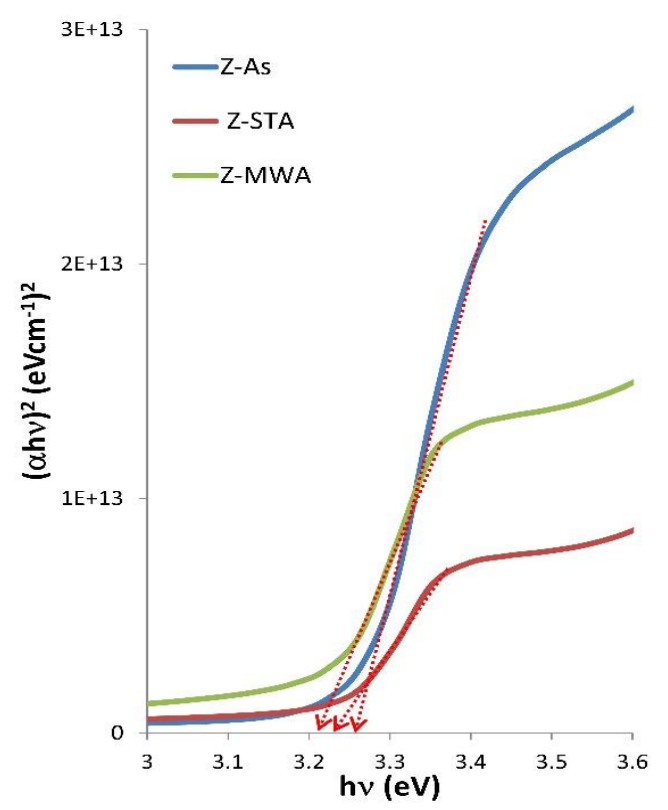

Figure 6. $(\alpha h v)^{2}-(h v)$ plots of Z-As, Z-STA, and Z-MWA films 
The room temperature photoluminescence (PL) spectra of the as-deposited and annealed $\mathrm{ZnO}$ films on glass substrate with a $325 \mathrm{~nm}$ excitation wavelength have been illustrated in Figure 7. From the spectra, it can be seen that the numbers, positions, and intensities of the PL peaks are affected by annealing. For Z-As film, the PL spectrum consists of two emission bands that indicate the strong UV emission band at $\sim 390 \mathrm{~nm}$ $(3.18 \mathrm{eV})$, and weak green emission band $\sim 514 \mathrm{~nm}(2.41 \mathrm{eV})$, respectively. The band emission emerging in the UV range is due to the excitonic recombination, while the band emissions existing at the visible range are due to the recombination of deep-level holes and electrons [38]. It is known from the literature that these deep level emissions are related to the point defects occurring during the production of crystallites and/or related to the change of crystallinity due to the zinc interstitials $\left(Z n_{i}\right)$, zinc vacancies $\left(Z n_{v}\right)$, oxygen interstitials $\left(O_{i}\right)$, oxygen vacancies $\left(O_{v}\right)$, and dislocations [39]. After the annealing of $\mathrm{ZnO}$ films by two different techniques, it has been observed that the intensity of the UV emission band decreased abruptly and shifted to lower wavelengths (blue shift). This shifting is stated in the literature that the change of stress along the lattice distortion in accordance with the XRD analysis [40]. On the other hand, new strong and narrow emissions have been determined for Z-STA and Z-MW films in the visible range of the spectrum $\sim 503 \mathrm{~nm}, \sim 528 \mathrm{~nm}$ (green emission bands), $\sim 662 \mathrm{~nm}$ and $\sim 650 \mathrm{~nm}$ (orange-red emission bands), respectively. Increasing in the visible emissions (green and/or orange-red emissions) of $\mathrm{ZnO}$ have been associated with the oxygen defects like excess oxygen concentrations and oxygen interstitials by the effect of annealing in oxygen ambient in the literature [41-44].

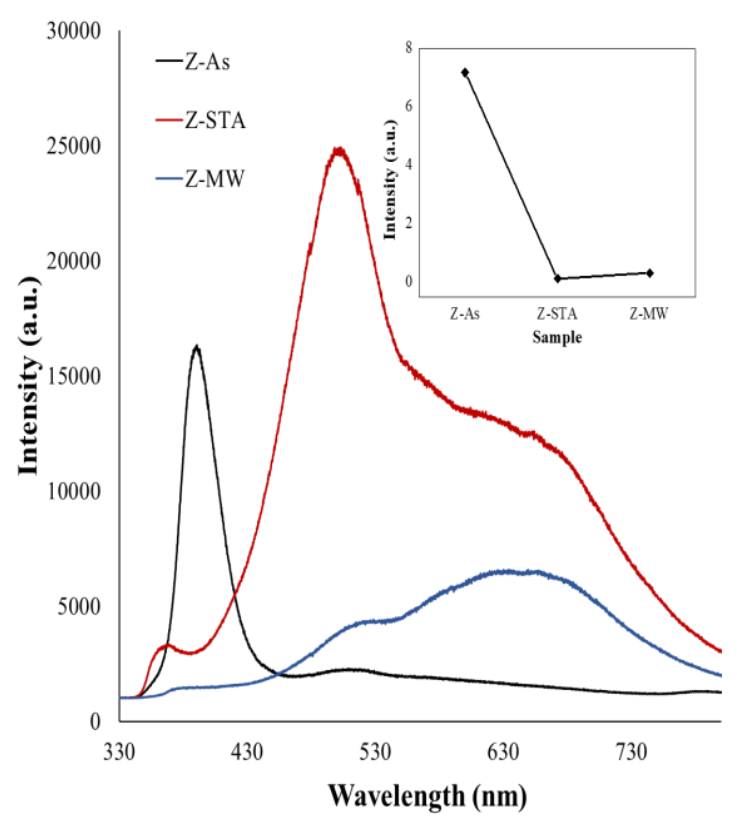

Figure 7. Absorbance spectra of Z-As, Z-STA, and Z-MWA films

The inset of Figure 7 shows the UV to green emission peak ratios as a function of annealing techniques. The intensity ratio of UV to green emission peaks has been determined as 7.18, 0.14 , and 0.33 for Z-As, ZSTA, and Z-MW films, respectively. Decreasing in this ratios for annealed films indicates the increasing amount of point defects in the $\mathrm{ZnO}$ film. However, an increase more than 2 times has been observed for the intensity ratios of Z-MW according to Z-STA film. This indicates the microwave annealing is more effective at producing a less defective structure and/or in reducing point defects in the $\mathrm{ZnO}$ film structure. Although the point defects in the material structure are generally expected to decrease as a result of the annealing process, in the current study the increase in the point defects is thought to be due to rearrangements of crystal structure/phase transitions between the (002) to (100) diffraction planes as seen in the XRD analysis. 


\section{CONCLUSION}

In this work, the effect of the annealing technique on the properties of $\mathrm{ZnO}$ films has been investigated. $\mathrm{ZnO}$ films have been deposited on glass substrates by Ultrasonic Spray Pyrolysis Technique. Then two different techniques which are STA and MWA techniques have been applied for thermal annealing. X-ray diffraction analyzes have been shown improved crystallinity levels for annealed films, especially that microwave annealing. After the annealing, alterations in the preferential orientations of $\mathrm{ZnO}$ films have been observed from (002) to (100) diffraction planes. Microstrain and dislocation density values of $\mathrm{ZnO}$ films reduced after the annealing of $\mathrm{ZnO}$ films with both annealing techniques. Root-like morphology has been detected when looking at the smooth and homogeneous surface of the films in detail at higher magnifications. An increase in this root-like morphology has been observed, resulting in an interconnected network structure. Increased $\mathrm{O} / \mathrm{Zn}$ ratios obtained for annealed films from all investigated regions indicate the improved elemental distribution in the film structure. Annealed films have been exhibited a decrease in the optical band gaps according to Z-As film from $3.27 \mathrm{eV}$ to $3.23 \mathrm{eV}$, and $3.21 \mathrm{eV}$, respectively. PL spectra of the films have been presented the point defect behavior in the structure of the films after the annealing and indicated the microwave annealing decreases the oxygen related point defect density according to standard thermal annealing technique. In annealed films, while Z-STA film presents the better stoichiometry on plan-view, and lower microstains and higher crystallite size in the crystal structure, ZMWA film draw attention with the properties of higher crystalline level, lower dislocation and point defect densities, crystal properties closest to standard, and lower optical band gap values. So, it can be said that microwave annealing is a more suitable technique for producing higher quality $\mathrm{ZnO}$ films for many applications like higher crystal quality optical materials used in photocatalysis.

\section{CONFLICTS OF INTEREST}

No conflict of interest was declared by the author.

\section{REFERENCES}

[1] Pearton, S. J., Norton, D. P., Ip, K., Heo, Y. W., Steiner, T., "Recent progress in processing and properties of ZnO", Progress in Materials Science, 50: 293-340, (2005).

[2] Triboulet, R., and Perrière, J., "Epitaxial growth of $\mathrm{ZnO}$ films", Progress in Crystal Growth and Characterization of Materials, 47(2-3): 65-138, (2003).

[3] Hoffman R. L, Norris, B. J., Wager, J. F., "ZnO-based transparent thin film transistors”, Applied Physics Letters, 82(5): 733-735, (2003).

[4] Willander, M., Nur O., Zhao, Q., Yang, L., Lorenz, M., Cao, B., Z̃iga Pérez, J., Czekalla, C., Zimmermann, G., Grundmann, M., Bakin, A., Behrends, A., Al-Suleiman, M., El-Shaer, A., Che Mofor, A., Postels, B., Waag, A., Boukos, N., Travlos, A., Kwack, H., Guinard, J., Le Si Dang, D., "Zinc oxide nanorod based photonic devices: Recent progress in growth, lightemitting diodes and lasers", Nanotechnology, 20(33): 332001, (2009).

[5] Di Mauro, A., Fragalà, M. E., Privitera, V., Impellizzeri, G., "ZnO for application in photocatalysis: From thin films to nanostructures", Materials Science in Semiconductor Processing, 69: 44-51 (2017).

[6] Purica, M., Budianu, E., Rusu, E., Danila, M., Gavrila, R., Optical and structural investigation of $\mathrm{ZnO}$ thin films prepared by chemical vapor deposition (CVD)", Thin Solid Films, 403: 485$488,(2002)$.

[7] Wang, L., Zhang, X., Zhao, S., Zhou, G., Zhou, Y., Qi, J., "Synthesis of well-aligned ZnO nanowires by simple physical vapor deposition on c-oriented $\mathrm{ZnO}$ thin films without catalysts or additives," Applied Physics Letters, 86(2): 024108, (2005). 
[8] Bilgin, V., Kose, S., Atay, F., Akyuz, I., "The effect of Sn concentration on some physical properties of zinc oxide films prepared by ultrasonic spray pyrolysis", Journal of Materials Science, 40(8): 1909-1915, (2005).

[9] Gonullu, M. P., and Ates, H., "Atomik Katman Biriktirme Tekniğine Genel Bakış: $\mathrm{ZnO}, \mathrm{TiO}_{2}$ ve $\mathrm{Al}_{2} \mathrm{O}_{3}$ Filmlerin Üretimi”, Gazi Üniversitesi Fen Bilimleri Dergisi Bölüm C: Tasarım ve Teknoloji, 7(3): 649-660, (2019).

[10] Gao W., and $\mathrm{Li}, \mathrm{Z}$., "ZnO thin films produced by magnetron sputtering", Ceramics International, 30(7): 1155-1159, (2003).

[11] Perednis, D., and Gauckler, L. J., "Thin film deposition using spray pyrolysis", Journal of Electroceramics, 14(2): 103-111, (2005).

[12] Patil, P. S., "Versatility of chemical spray pyrolysis technique", Materials Chemistry and Physics, 59(3): 185-198, (1999).

[13] Bates, C. H., White, W. B., Roy, R., "New High-Pressure Polymorph of Zinc Oxide”, Science, 137: 993, (1962).

[14] Garnier, J., Bouteville, A., Hamilton, J., Pemble, M. E., Povey, I. M., “A comparison of different spray chemical vapour deposition methods for the production of undoped $\mathrm{ZnO}$ thin films", Thin Solid Films, 518(4): 1129-1135, (2009).

[15] Bacaksiz, E., Parlak, M., Tomakin, M., Özçelik, A., Karakiz, M., Altunbaş, M., "The effects of zinc nitrate, zinc acetate and zinc chloride precursors on investigation of structural and optical properties of ZnO thin films", Journal of Alloys and Compounds, 466(1-2): 447-450, (2008).

[16] Yoon S. H., and Kim, D. J., "Effect of substrate on the preferred orientation of $\mathrm{ZnO}$ films by chemical solution deposition", Journal of Crystal Growth, 303(2): 568-573, (2007).

[17] Salameh, B., Alsmadi, A. M., Shatnawi, M., "Effects of Co concentration and annealing on the magnetic properties of Co-doped $\mathrm{ZnO}$ films: Role of oxygen vacancies on the ferromagnetic ordering", Journal of Alloys and Compounds, 835: 155287, (2020).

[18] Chu, C. H., Wu, H. W., Huang, J. L., "Effect of annealing temperature and atmosphere on aluminum-doped $\mathrm{ZnO} / \mathrm{Au} /$ aluminum-doped $\mathrm{ZnO}$ thin film properties", Thin Solid Films, 605: 121-128, (2016).

[19] Goktas, A., "High-quality solution-based $\mathrm{Co}$ and $\mathrm{Cu}$ co-doped $\mathrm{ZnO}$ nanocrystalline thin films: Comparison of the effects of air and argon annealing environments", Journal of Alloys and Compounds, 735: 2038-2045, (2018).

[20] Cui, L., Zhang, H. Y., Wang, G. G., Yang, F. X., Kuang, X. P., Sun, R., Han, J. C., "Effect of annealing temperature and annealing atmosphere on the structure and optical properties of $\mathrm{ZnO}$ thin films on sapphire (0001) substrates by magnetron sputtering," Applied Surface Science, 258(7): 2479-2485, (2012).

[21] Xue, X. T., Gu, Y., Ma, H. P., Hang, C. Z., Tao, J. J., Lu, H. L., Zhang, D. W "Effect of rapid thermal annealing on the properties of zinc tin oxide films prepared by plasma-enhanced atomic layer deposition”, Ceramics International, 46(9): 13033-13039, (2020). 
[22] Kuşkonmaz N. and Kutbay, I., "Mikrodalga ısıtmanın seramik üretiminde kullanımı," Metalurji Dergisi, 137: 52-56, (2004).

[23] Atay, F., V, Bilgin., Akyuz, I., Kose, S., “The effect of in doping on some physical properties of CdS films", Materials Science in Semiconductor Processing, 6: 197-203, (2003).

[24] Barrett, C. S., and Massalski, T.B., Structure of Metals, 35, Third edition, Pergamon, Oxford, New York, 204, (1980).

[25] Bilgin, V., Akyuz, I., Ketenci, E., Kose, S., Atay, F., "Electrical, structural and surface properties of fluorine doped tin oxide films", Applied Surface Science, 256(22): 6586-6591, (2010).

[26] Abdallah, B., Jazmati, A. K., Refaai, R., "Oxygen effect on structural and optical properties of $\mathrm{ZnO}$ thin films deposited by RF magnetron sputtering”, Materials Research, 20(3): 607-612, (2017).

[27] Yue-Hui, H., Yi-Chuan, C., Hai-Jun, X., Hao, G., Wei-Hui, J., Fei, H., Yan-Xiang, W. "Texture $\mathrm{ZnO}$ thin-films and their application as front electrode in solar cells", Engineering, 2: 973-978, (2010).

[28] Xu, Li., Zhu, X., Yang, D., "Enhanced luminescent performance with surface wrinkled Aldoped $\mathrm{ZnO}$ films", Journal of Materials Science: Materials in Electronics, 31: 6304-6312, (2020).

[29] Sutanto, H., Durri, S., Wibowo, S., Hadiyanto, H., Hidayanto, E., "Rootlike morphology of ZnO:Al thin film deposited on amorphous glass substrate by sol-gel method", Physics Research International, 2016: 1-7, (2016).

[30] Navin, K. and Kurchania, R., "Structural, Morphological and Optical Studies of RippleStructured ZnO Thin Films", Applied Physics A: Materials Science and Processing, 121: 11551161, (2015).

[31] Kwon, S. J. Park, J. H., Park, J. G., "Wrinkling of sol-gel-derived thin Film”, Physical Review E 71: 011604, (2005).

[32] Scherer, G. W., "Sintering of sol-gel films", Journal of Sol-Gel Science and Technology 8(1): 353-363, (1997).

[33] Goniakowski, J., and Noguera, C., "Relaxation and rumpling mechanisms on oxide surfaces", Surface Science, 323(1-2): 129-141, (1995).

[34] Caglar, Y., Ilican, S., Caglar, M., Yakuphanoglu, F., "Effects of In, Al and Sn dopants on the structural and optical properties of ZnO thin films", Spectrochimica Acta Part A: Molecular and Biomolecular Spectroscopy, 67(3-4): 1113-1119, (2007).

[35] Sengupta, J., Sahoo, R. K., Bardhan, K. K., Mukherjee, C. D., "Influence of annealing temperature on the structural, topographical and optical properties of sol-gel derived $\mathrm{ZnO}$ thin films", Materials Letters, 65(17-18): 2572-2574, (2011).

[36] Ghosh, R., Basak, D., Fujihara, S., "Effect of substrate-induced strain on the structural, electrical, and optical properties of polycrystalline $\mathrm{ZnO}$ thin films", Journal of Applied Physics, 96(5): 2689-2692, (2004). 
[37] Ramírez-Ortega D., Meléndez, A. M., Acevedo-Peña, P., González, I., Arroyo, R., "Semiconducting properties of $\mathrm{ZnO} / \mathrm{TiO}_{2}$ composites by electrochemical measurements and their relationship with photocatalytic activity”, Electrochimica Acta, 140: 541-549, (2014).

[38] Hong, R., Qi, H., Huang, J., He, H., Fan, Z., \& Shao, J., "Influence of oxygen partial pressure on the structure and photoluminescence of direct current reactive magnetron sputtering $\mathrm{ZnO}$ thin films", Thin Solid Films, 473(1): 58-62, (2005).

[39] Djurišić, A. B., Choy, W. C., Roy, V. A. L., Leung, Y. H., Kwong, C. Y., Cheah, K. W., Gundu Rao, T. K., Chan, W. K., Fei Lui, H., Surya, C., "Photoluminescence and electron paramagnetic resonance of ZnOtetrapod structures", Advanced Functional Materials, 14(9): 856-864, (2004).

[40] Nehru, L. C., Umadevi, M., Sanjeeviraja, C., "Studies on structural, optical and electrical properties of $\mathrm{ZnO}$ thin films prepared by the spray pyrolysis method". International Journal of Materials Engineering, 2(1): 12-17, (2012).

[41] Djurišić, A. B., Leung, Y. H., Tam, K. H., Hsu, Y. F., Ding, L., Ge, W. K., Zhong, Y. C., Wong, K. S., Chan, W. K., Tam, H. L., Cheah, K. W., Kwok, W. M., Phillips, D. L., "Defect emissions in ZnO nanostructures", Nanotechnology, 18(9): 095702(8pp), (2007).

[42] Zhang, X., Qin, J., Xue, Y., Yu, P., Zhang, B., Wang, L., Liu, R., "Effect of aspect ratio and surface defects on the photocatalytic activity of $\mathrm{ZnO}$ nanorods", Scientific reports, 4(1): 1-8, (2014).

[43] Peng, W. Q., Qu, S. C., Cong, G.W., Wang, Z. G., "Structure and visible luminescence of ZnO nanoparticles", Materials Science in Semiconductor Processing, 9(1-3): 156-159, (2006).

[44] Panigrahy, B., Aslam, M., Misra, D. S., Ghosh, M., Bahadur, D., "Defect-related emission and magnetization properties of ZnO Nanorods", Advanced Functional Materials, 20(7): 11611165, (2010). 